\title{
Bone marrow characterization in COPD: a multi-level network analysis
}

\author{
Nuria Toledo-Pons ${ }^{1,2}$, Guillaume Noell ${ }^{1,3}$, Andreas Jahn², Amanda Iglesias ${ }^{1,2}$, Maria Antonia Duran ${ }^{4}$, Julio Iglesias $5^{5}$,
} Angel Rios ${ }^{2}$, Sergio Scrimini ${ }^{2}$, Rosa Faner ${ }^{1,3}$, Orlando Gigirey ${ }^{6}$, Alvar Agustí $1^{1,3,7,8}$ and Borja G. Cosío ${ }^{1,2^{*}}$ (i)

\begin{abstract}
Background: Bone marrow (BM) produces hematopoietic and progenitor cells that contribute to distant organ inflammation and repair. Chronic obstructive pulmonary disease (COPD) is characterized by defective lung repair. Yet, BM composition has not been previously characterized in COPD patients.
\end{abstract}

Methods: In this prospective and controlled study, BM was obtained by sternum fine-needle aspiration in 35 COPD patients and 25 healthy controls (10 smokers and 15 never-smokers). BM cell count and immunophenotype were determined by microscopy and flow cytometry, respectively. Circulating inflammatory (C-reactive protein, IL-6, IL-8) and repair markers (HGF, IGF, TGF- $\beta$, VEGF) were quantified by ELISA. Results were integrated by multi-level network correlation analysis.

Results: We found that: (1) there were no major significant pair wise differences between COPD patients and controls in the BM structural characteristics; (2) multi-level network analysis including patients and controls identifies a relation between immunity, repair and lung function not previously described, that remains in the COPD network but is absent in controls; and (3) this novel network identifies eosinophils as a potential mediator relating immunity and repair, particularly in patients with emphysema.

Conclusions: Overall, these results suggest that BM is activated in COPD with impaired repair capacity in patients with more emphysema and/or higher circulating eosinophils.

Keywords: COPD, Bone marrow, Eosinophil, Network

\section{Background}

The human bone marrow (BM) produces hematopoietic cells that contribute to the inflammatory response [1], as well as hematopoietic stem cells (HSC; CD34+) and endothelial progenitor cells (EPC; CD34+ CD133+ KDR + ) that can migrate to distant tissues, such as the lungs, and modulate both the inflammatory response and tissue repair [2-5].

The role of some repair markers and growth factors have been studied in COPD patients or pre-clinical COPD models. It has been described that human mesenchymal stromal cells exert hepatocyte growth factor (HGF) dependent cytoprotective effects in a human relevant

\footnotetext{
* Correspondence: borja.cosio@ssib.es

${ }^{1}$ CIBER Enfermedades Respiratorias (CIBERES), Instituto de Salud Carlos III,

Madrid, Spain

${ }^{2}$ Department of Respiratory Medicine, Hospital Universitari Son

Espases-IdISBa, Valldemossa 79, 07010 Palma de Mallorca, Spain

Full list of author information is available at the end of the article
}

pre-clinical model of COPD [6]. Also, impaired vascular endothelial growth factor (VEGF) signalling has been associated with emphysema in animal models [7]. Recently, a possible novel role of insulin-like growth factor (IGF) has been described. IGF participate in the control of airway epithelial cell differentiation and the bronchiolar airway epithelial repair kinetics regulation after injury in various pulmonary diseases, such as asthma and COPD [8]. Finally, the transforming growth factor-beta (TGF- $\beta$ ) family regulates cell proliferation, differentiation, extracellular matrix synthesis, and apoptosis. Attenuation of TGF- $\beta$ signalling leads to pulmonary emphysema in animal models [9] and has been shown to be decreased in the bronchiolar epithelium in patients with stable COPD compared with control smokers with normal lung function [10].

Chronic obstructive pulmonary disease (COPD) is characterized by both pulmonary and systemic inflammation, 
as well as by defective lung repair [11]. Indirect evidence supports the hypothesis that BM function in COPD is altered, as suggested by the reduced number of circulating-HSC and EPC in these patients [12], particularly in those with more severe airflow limitation [13] and low body mass index (BMI) values [14]. However, a recent small study did not identify significant differences in BM progenitor cell markers between 9 COPD patients and 9 age-matched, never-smoking controls [15]. Accordingly, in the present study we sought to use a holistic approach (network analysis [16]) to compare the characteristics of BM (and circulatory inflammation and repair markers) in a larger series of COPD patients and smoking and never-smoking controls with normal spirometry. Further, because patients with emphysema generally have severe airflow limitation and low BMI values [16], we hypothesized that differences would be magnified in these subgroup of patients. Finally, given that high circulating eosinophil levels (Eos), another BM-derived cell, seem to relate to clinical outcomes in COPD [17, 18], we also contrasted COPD patients with less or $\geq 300$ circulating Eos/ $\mu \mathrm{L}$.

\section{Methods}

\section{Study design and ethics}

We included in this prospective and controlled study 35 clinically stable COPD patients defined by GOLD criteria [11] and 25 healthy controls (10 current smokers and 15 never smokers with normal spirometry) who required planned cardio-thoracic surgery for clinical reasons (COPD and smoker controls had indication for lung resection due to lung nodule or cancer by thoracic surgery and never-smoker controls had indication for valve replacement by cardiac surgery).

\section{Lung function}

Forced spirometry, static lung volumes and carbon monoxide diffusing capacity (DLCO) were determined following international recommendations, using Mediterranean reference values $[19,20]$ in the pre-anaesthetic visit before surgery.

\section{Bone marrow harvesting and analysis}

Sternum fine-needle (18G) BM aspiration (3-5 ml) was performed by an expert haematologist in the surgical theatre, once the patient was under general anaesthesia and before the sternotomy. Fresh BM smears were used for direct cell count (only in COPD patients). A $50 \mu \mathrm{l}$ BM sample was diluted 1:4 in 1× PBS (pH 7,4; PAA) and analyzed using CELL-DYN Sapphire (Abbot, USA) to determine cell types distribution. HSC and EPC were isolated from fresh BM aspirates using a RosetteSep Kit (STEMCELL Technologies Inc., Canada) following manufacturer's instructions to obtain a more representative sample. Cells were quantified by flow cytometry on a FACScan (Coulter Epics XL-MCL; Beckmann Coulter) by the presence of antigens CD34 (BD Pharmingen, NJ, USA), KDR (R\&D Systems, Minneapolis, USA), CD133 (Miltenyi Biotec, Germany), c-kit, Ki67 (Abcam, Cambridge, UK). Gates were set to detect CD34+ cells and to evaluate co-expressions of CD34+ cells with CD 133, KDR, c-kit and Ki67. At least 20.000 events were acquired for each sample. Following previous publications [2-4], EPCs were also identified by FACS as CD34+ CD133+ KDR+ cells. The remaining BM sample were centrifuged at $1800 \mathrm{rpm} / 5 \mathrm{~min} / 4{ }^{\circ} \mathrm{C}$ to separate cells from plasma and the supernatant was stored $(100 \mu \mathrm{l}$ aliquots) at $-80{ }^{\circ} \mathrm{C}$ until cytokine analysis.

\section{Circulating inflammatory and tissue repair markers}

Circulating blood $(10 \mathrm{ml})$ was collected in tubes with or without EDTA by venipuncture before anaesthesia. Total and differential leukocyte counts were determined automatically (Sysmex K-4500, Toa Medical Electronics Co Ltd., Kobe, Japan). Blood was allowed to clot and serum was separated by centrifugation at $3000 \mathrm{rpm}$ for $15 \mathrm{~min}$ at $4{ }^{\circ} \mathrm{C}$ and stored at $-80^{\circ} \mathrm{C}$ until analysis. The concentration of IL-6 (Labclinics, Barcelona, Spain), IL-8 (Invitrogen, California, USA), VEGF (Ebioscience), TGF- $\beta$ (Ebioscience), IGF (R\&D Systems) and HGF (Invitrogen) in plasma (and BM supernatant) were determined by ELISA. Assay sensitivities, as expressed by the manufacturer, were: $0.03 \mathrm{pg} / \mathrm{ml}$ for $\mathrm{IL}-6,<100 \mathrm{fg} / \mathrm{ml}$ for IL-8, $7.9 \mathrm{pg} / \mathrm{ml}$ for VEGF, $8.6 \mathrm{pg} / \mathrm{ml}$ for TGF- $\beta$, $0.056 \mathrm{ng} / \mathrm{mL}$ for IGF and $20 \mathrm{pg} / \mathrm{ml}$ for HGF. C-reactive protein (CRP) concentration was determined by Nephelometry.

\section{Data and network analysis}

Results are expressed as mean \pm standard deviation, or median [interquartile range] values. ANOVA (or Kruskall-Wallis test) and unpaired t-test (or Mann-Whitney U-tests) were used to compare normally (and abnormally) distributed variables. Bivariate correlations were tested with Spearman test. Differences were considered statistically significant at 2-tailed $p<0.05$ and the stronger of these Spearman relationships (threshold $p$-value $<0.01$ ) between clinical and biological variables were plotted together as multi-level networks by representing variables as nodes and correlations between them as edges as previously described [21-23]. These correlation networks were constructed with custom $\mathrm{R}$ scripts and Cytoscape [24]. The multi-level network includes variables from multiple levels (or categories), including clinical, lung function, BM and circulating blood information. Each node in the network corresponds to a specific variable (see names) whose colour denotes the level to which it belongs (see legends). Nodes are linked by edges only if their Spearman correlation was statistically significant $(p<0.01)$, either positively (continuous lines) or negatively (dashed 
lines). The thickness of the edge is proportional to the correlation coefficient (Rho) (see legends). Grey shaded areas highlight 5 isolated modules (or sub-networks) that are named arbitrarily based on the assessment by the investigators of the type of variables included in each of them. In order to compare different biological effects, we built different networks comparing COPD and controls, COPD with $\mathrm{DLCO}<$ $60 \%$ or $\geq 60 \%$, COPD with blood eosinophils $<300$ or $\geq 300$ cells $/ \mu \mathrm{L}$, and COPD with a smoking history $<45$ or $\geq$ pack-years.

\section{Results}

\section{Bivariate comparisons across groups}

Table 1 presents the main demographic and clinical characteristics of the three groups studied. By design, smoking history and lung function values were different between them. BMI was higher in never smokers $(p<$ 0.05). COPD patients had moderate-severe airflow limitation, gas trapping and reduced DLCO.

The percentages of cells expressing immune-phenotypic (HSC (CD34+) and EPC (CD34+ CD133+ KDR+)) or proliferation and differentiation markers (Ki67+, c-kit+) were similar pair wisely across groups (Table 2). Likewise, we did not find significant differences between groups in inflammatory or repair biomarkers, neither in BM or circulating blood, with the exception of increased CRP levels in COPD patients and elevated circulating neutrophils in smokers (Table 2).

\section{Multi-level network analysis All participants}

We first built a multi-level correlation network (Fig. 1) that included all participants $(n=60)$. The following observations are worth noting in Fig. 1: (\#1) the Bone Marrow module has 11 nodes, all of them corresponding to BM measurements; (\#2) the Lung Function module is the largest one $(n=13)$ and relates, as expected, FEV1, DLCO and BMI. Interestingly, it also includes several growth factors (HGF in BM as well as HGF, VEGF, IGF in peripheral blood), repair factors (TGF- $\beta$ ) and the percentatge of BM EPCs. Besides, circulating Eos relate inversely to both FEV1 and DLCO; (\#3) the Immunity-Repair module relates the percentage of BM lymphocytes, B cells (CD19) and Eos with that of HSC (CD34); (\#4) the Blood module includes a well defined sub-network of absolute counts of circulating cells, to some extend equivalent to those found in \#1 (Bone Marrow), which included only BM markers; and, finally, (\#5) the $M \phi$ (Macrophage) module, relates the levels of BM metamyelocytes and Monocytes/ M $\phi$. All in all, these observations indicate the existence of a number of modules that can be "expected" physiologically (\#1, \#4-\#5), but highlight that of some "unexpected" modules (\#2 Lung function and \#3 the Immunity-Repair module) that are really multi-level and relate clinical, functional, BM and circulating markers of relevance in the context of the present analysis.

\section{Comparison across groups: COPD vs. controls}

Figure 2 presents the correlation networks determined independently in COPD patients $(n=35)$, Smokers $(n=$ $10)$ and Never-smokers $(n=15)$. It is important to note from the outset that the different number of individuals included in each network can modulate its structure, since the possibility of identifying significant correlations increases with sample size [25]. With this caveat in mind, Fig. 2 shows greater number of inter-connected nodes involved in the COPD network and that this network incorporates lung function variables, BM and blood markers of inflammation and repair that are not observed in controls (Fig. 2). To address the potential confounding effect of sample size differences, we increased the sample size of the control network by merging smokers and never smokers with normal spirometry $(n=25)$. Additional file 1: Figure S1 confirms that the COPD network continues to be more interconnected that that of merged controls, suggesting a higher level of system activation. Of note, FEV1, DLCO and circulating Eos are clearly related in COPD patients. Also, to assess the potential confounder effect of differential

Table 1 Demographic and clinical characteristics (mean \pm SD) of participants. Bolded italic text highlight variables with statistically significant differences $(p \leq 0.05)$

\begin{tabular}{|c|c|c|c|c|}
\hline & Never-smokers $(n=15)$ & Smokers $(n=10)$ & $\operatorname{COPD}(n=35)$ & $P$-value \\
\hline Age, years & $62.50 \pm 16.69$ & $63.95 \pm 10.36$ & $66.35 \pm 8.10$ & 0.35 \\
\hline$B M I, k g / m^{2}$ & $33.00 \pm 4.96$ & $27.86 \pm 4.36$ & $27.05 \pm 4.20$ & $<0.01$ \\
\hline Pack years & $0.00 \pm 0.00$ & $45.4 \pm 22.82$ & $51.0 \pm 26.03$ & $<0.01$ \\
\hline FEV1, \% reference & $105.61 \pm 14.53$ & $100.88 \pm 14.01$ & $64.26 \pm 20.79$ & $<0.01$ \\
\hline FEV1/FVC, \% & $79.29 \pm 6.18$ & $78.47 \pm 5.29$ & $53.84 \pm 13.74$ & $<0.01$ \\
\hline$R V, \%$ reference & $112.8 \pm 25.10$ & $99.88 \pm 23.69$ & $172.41 \pm 56.27$ & $<0.01$ \\
\hline DLCO, \% reference & $91.21 \pm 24.01$ & $82.79 \pm 13.90$ & $60.79 \pm 17.15$ & $<0.01$ \\
\hline
\end{tabular}

BMI Body mass index, FEV1 Forced expiratory volume in 1st second, FVC Forced vital capacity, RV Residual volume, DLCO Diffusing capacity of the lung for carbon monoxide 
Table 2 Pair wise comparison of BM and circulating inflammatory and repair markers (median [IQR] or mean $\pm S D$ ) in the three groups studied. Bolded italic text highlights variables with statistically significant differences $(p \leq 0.05)$

\begin{tabular}{|c|c|c|c|c|}
\hline & Never-smokers $(n=15)$ & Smokers $(n=10)$ & $\operatorname{COPD}(n=35)$ & ANOVA (or KW) $P$ Value \\
\hline \multicolumn{5}{|l|}{ BM CHARACTERIZATION } \\
\hline \multicolumn{5}{|l|}{ Immunophenotype } \\
\hline CD3\% & $5.00[5.00-6.00]$ & $5.50[3.30-7.00]$ & 6.00 [4.00-9.50] & 0.59 \\
\hline CD5\% & $5.00[5.00-6.00]$ & $5.00[3.00-7.00]$ & 6.00 [4.30-9.80] & 0.40 \\
\hline CD7\% & $7.00[5.30-8.00]$ & 6.00 [4.00-9.00] & 6.00 [5.00-9.80] & 0.78 \\
\hline CD10\% & 20.00 [13.00-26.00] & 19.00 [15.00-28.50] & 19.50 [15.80-25.80] & 0.79 \\
\hline CD19+\% & $3.00[2.00-4.50]$ & $3.00[2.00-6.30]$ & $3.00[2.00-4.00]$ & 0.57 \\
\hline $\mathrm{CD} 19+\mathrm{CD} 10+\%$ & $2.00[1.30-3.00]$ & $0.50[0.50-2.50]$ & 2.00 [1.00-2.00] & 0.62 \\
\hline CD33\% & 76.00 [68.50-80.00] & 68.50 [61.30-79.00] & 71.50 [65.00-80.00] & 0.47 \\
\hline CD13\% & 34.50 [30.00-39.50] & $30.00[20.00-40.00]$ & 30.00 [25.00-33.00] & 0.43 \\
\hline CD14\% & $2.00[1.30-3.80]$ & $3.00[2.00-4.00]$ & $3.00[2.00-4.00]$ & 0.31 \\
\hline CD15\% & 70.00 [57.50-75.00] & $62.50[56.30-73.80]$ & 65.00 [60.00-70.00] & 0.70 \\
\hline CD117\% & $2.00[1.50-2.00]$ & $2.00[2.00-2.80]$ & $2.00[2.00-2.80]$ & 0.40 \\
\hline CD34\% & $1.00[1.00-2.00]$ & $2.00[1.00-2.80]$ & $1.00[1.00-2.00]$ & 0.50 \\
\hline DR\% & $8.00[4.50-11.00]$ & $9.50[7.30-10.00]$ & 8.00 [7.503-10.00] & 0.81 \\
\hline CD4\% & $3.00[3.00-3.00]$ & $3.00[2.00-3.40]$ & $3.50[3.00-4.80]$ & 0.24 \\
\hline CD8\% & $2.00[2.00-3.00]$ & $2.00[1.30-4.00]$ & $3.00[2.00-4.00]$ & 0.66 \\
\hline CD56\% & $1.00[1.00-1.80]$ & $1.00[1.00-2.00]$ & $1.00[1.00-1.00]$ & 0.83 \\
\hline sCD64\% & $3.00[1.50-5.00]$ & $3.00[2.00-4.00]$ & $3.00[2.00-4.00]$ & 0.88 \\
\hline \multicolumn{5}{|c|}{ Progenitor cell surface markers } \\
\hline \multicolumn{5}{|l|}{ CD34 } \\
\hline$\%$ & $7.38[2.28-16.23]$ & 13.44 [10.50-18.02] & $14.50[9.83-24.10]$ & 0.07 \\
\hline MFI & 164.60 [110.50-202.80] & 118.03 [54.99-335.73] & $92.65[65.85-113.10]$ & 0.09 \\
\hline \multicolumn{5}{|l|}{ CD $34+$ c-kit+ } \\
\hline$\%$ & $76.40[67.00-85.40]$ & 65.98 [57.88-79.71] & 81.90 [66.80-84.70] & 0.41 \\
\hline MFI & 24.70 [19.60-39.65] & 19.95 [15.85-70.73] & $38.10[24.80-55.40]$ & 0.36 \\
\hline \multicolumn{5}{|l|}{ CD $34+\mathrm{Ki} 67+$} \\
\hline$\%$ & $69.40[30.30-77.40]$ & 83.30 [59.99-97.64] & 96.80 [73.30-97.90] & 0.72 \\
\hline MFI & 31.80 [22.35-52.90] & $28.00[21.75-70.65]$ & 50.30 [43.30-74.30] & 0.32 \\
\hline \multicolumn{5}{|l|}{$\mathrm{CD} 34+133+\mathrm{KDR}+$} \\
\hline$\%$ & $1.10[0.00-3.05]$ & $1.23[0.18-1.80]$ & $4.35[1.58-7.73]$ & 0.51 \\
\hline $\mathrm{MFI}$ & 78.00 [37.93-127.15] & $112.40[74.48-134.73]$ & 49.25 [40.10-120.60] & 0.33 \\
\hline \multicolumn{5}{|c|}{ INFLAMMATORY AND REPAIR MARKERS } \\
\hline \multicolumn{5}{|l|}{ BM Supernatant } \\
\hline IL6 pg/ml & $12.20[1.30-23.00]$ & $13.06[1.65-27.39]$ & $9.80[7.60-24.90]$ & 0.06 \\
\hline IL-8 pg/ml & $6.50[3.90-10.70]$ & $7.10[3.00-8.70]$ & $3.60[2.40-10-90]$ & 0.48 \\
\hline $\mathrm{HGF} \mathrm{pg} / \mathrm{ml}$ & $2854.07[646.71-22,718.86]$ & 1290.97 [909.37-9284.43] & 1689.59 [692.43-2466.46] & 0.63 \\
\hline \multicolumn{5}{|l|}{ Circulating blood } \\
\hline Leucocytes $\times 10 \wedge^{9} / \mathrm{L}$ & $7.67 \pm 3.43$ & $8.41 \pm 2.45$ & $7.41 \pm 1.88$ & 0.52 \\
\hline Neutrophils \% & $55.07 \pm 18.58^{*}$ & $71.98 \pm 11.92$ & $61.69 \pm 11.85$ & 0.02 \\
\hline Eos $\%$ & $2.13 \pm 1.77$ & $1.46 \pm 1.19$ & $3.14 \pm 1.65^{+}$ & 0.01 \\
\hline CRP $\mathrm{mg} / \mathrm{dl}$ & $1.62 \pm 2.05$ & $0.90 \pm 2.19$ & $5.65 \pm 12.57^{*}$ & 0.02 \\
\hline IL-6 pg/ml & $0.10[0.10-0.10]$ & $0.10[0.00-0.10]$ & $0.10[0.1-0.20]$ & 0.14 \\
\hline
\end{tabular}


Table 2 Pair wise comparison of BM and circulating inflammatory and repair markers (median $[\mathrm{IQR}]$ or mean $\pm \mathrm{SD}$ ) in the three groups studied. Bolded italic text highlights variables with statistically significant differences $(p \leq 0.05)$ (Continued)

\begin{tabular}{cllll}
\hline & Never-smokers $(n=15)$ & Smokers $(n=10)$ & COPD $(n=35)$ & ANOVA (or KW) $P$ Value \\
\hline $\mathrm{IL}-8 \mathrm{pg} / \mathrm{ml}$ & $1.40[0.90-2.50]$ & $2.80[1.30-5.90]$ & $2.30[1.5-3.10]$ & 0.82 \\
\hline
\end{tabular}

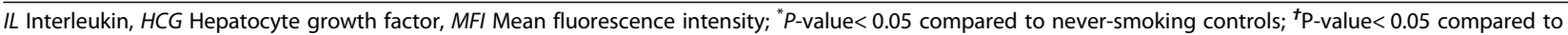
smoking controls; ${ }^{*} P$-value $<0.05$ compared to never-smoking and smoking controls

sample size on network density comparisons, we performed patients sub-sampling analysis in COPD or Controls. For each group, we averaged correlations coefficients and $p$-values of $n=1000$ random subgroups of patients of $n=25$, and observed that the difference in density is not due to differential sample size.

\section{COPD phenotypes: Emphysema and circulating eosinophils}

To get further insight into the relationship between emphysema, circulating Eos $[26,27]$ and $\mathrm{BM}$ response in COPD, as established a priori in the analysis plan, we first compared the results obtained in COPD patients with DLCO values higher or lower than $60 \%$ of reference, a well-established surrogate marker of emphysema [16]. As expected [16], lung function was worse in the latter patients (Additional file 3: Table S1). In patients with $\mathrm{DLCO} \geq 60 \%$ ref., bone marrow cellularity was enriched in white blood cells and segmented neutrophils (Additional file 3: Table S1). By contrast, the network was less structured in patients with $\mathrm{DLCO}<60 \%$ ref., suggesting less network resilience [21] and impaired repair capacity in patients with emphysema (Additional file 2: Figure S2). Of

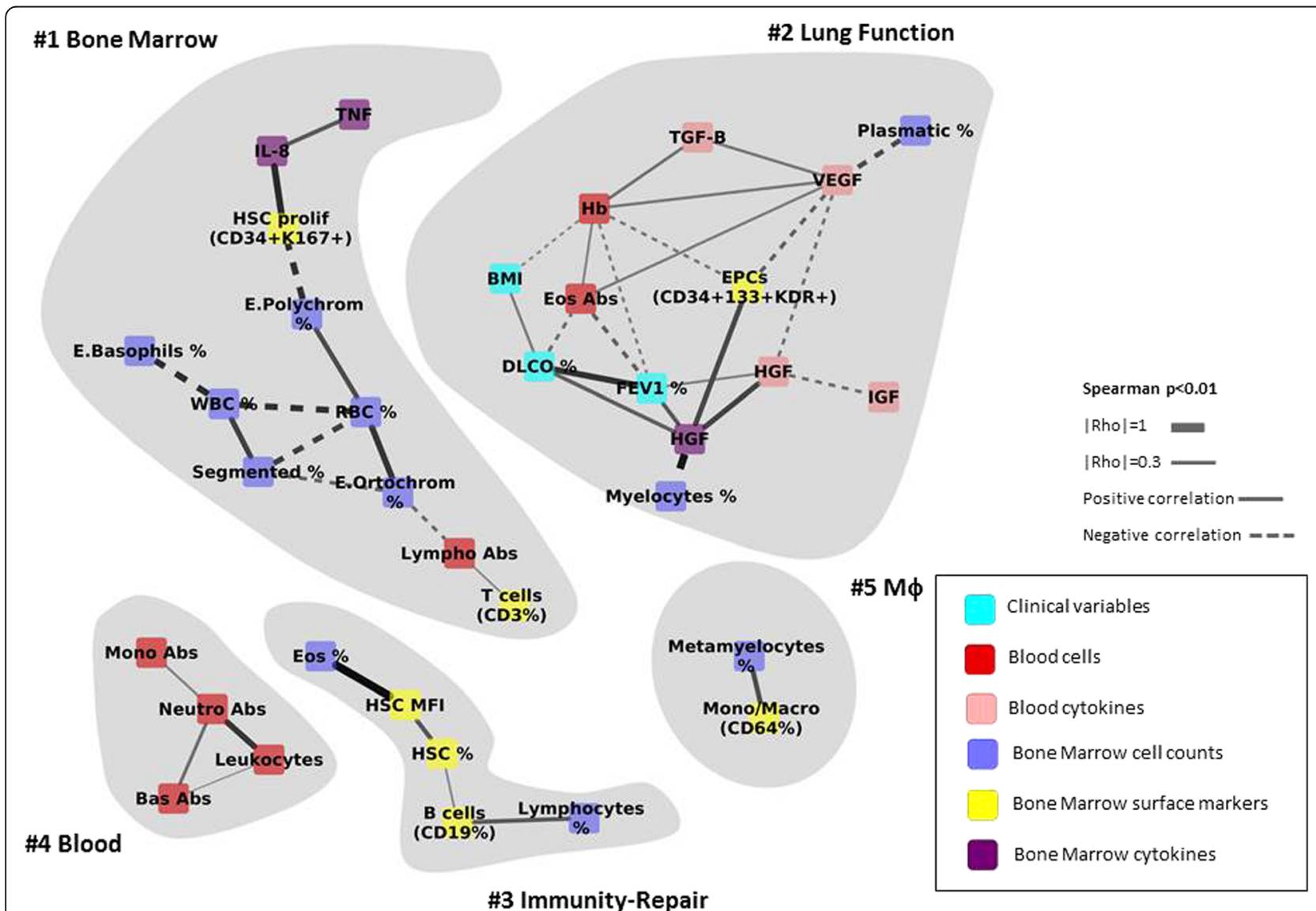

Fig. 1 Multi-level correlation network that includes all participants in the study. For further explanations, see text. Abbreviations: Abs: absolute count; HSC: Hematopoietic stem cells; EPC: Endothelial progenitor cells; TNF: Tumour necrosis factor; TGF-ß: Transforming growth factor beta; VEGF: Vascular endothelial growth factor; IGF: Insulin-like growth factor; IL: Interleukin; RBC: Red blood cells; WBC: White blood cells; Lympho: Lymphocytes; Segmented: segmented neutrophils; E. Polychrom: Polychromatic erythroblast; E. Basophils: Basophils erythroblast; E. Ortochrom: Ortochromatic erythroblast; T cells: T lymphocytes; B cells: B lymphocytes; Plasmatic: Plasmatic cells; Hb: haemoglobin; Eos: Eosinophils; Mono/ Macro: Monocyte/Macrophages; MFI: Mean fluorescence intensity; Mono: Monocyte; Neutro: Neutrophil; Bas: Basophil; M $\varphi$ : Macrophage; FEV1: forced expiratory volume in 1st second; DLCO: Diffusing capacity of the lung for carbon monoxide; BMI: body mass index 


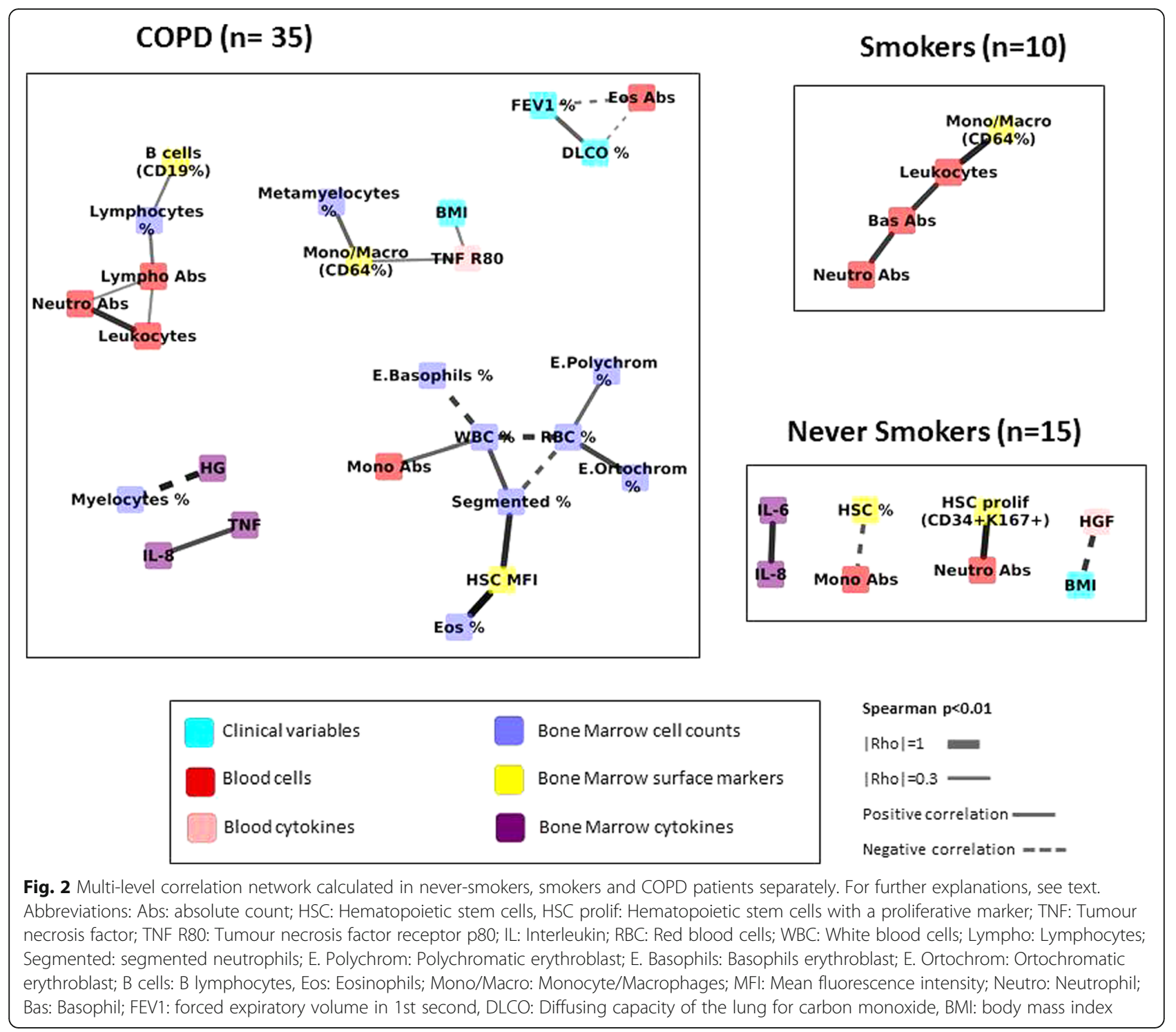

note, circulating Eos were higher in these latter patients (Additional file 3: Table S1).

Secondly, we compared the network characteristics of COPD patients with less or $\geq 300$ Eos/ $\mu \mathrm{L}$ (Additional file 3: Table S2). The latter patients showed worse lung function and a reduced proportion of BM plasma cells and CD34+ c-kit+, as well as circulating neutrophils. The remaining $\mathrm{BM}$ and circulatory markers were similar in both groups. Additional file 4: Figure S3 shows that the multilevel correlation network was less well structured in patients with $\geq 300$ circulating Eos $/ \mu \mathrm{L}$, suggesting again less resilience of the system [21].

\section{Discussion}

The major novel findings of this study were that: [1] there were no major significant individual pair wise differences between COPD patients, smokers and never-smoker controls in the composition of immune-phenotypic, proliferation and differentiation, inflammatory or repair markers, neither in BM or circulating blood; [2] the novel multi-level correlation network approach used here identified (in all participants) a relation between immunity, repair and lung function not previously described; [3] network analysis also showed a greater number of interconnected nodes in COPD patients than in controls, with the presence of immunity and repair nodes not include in the network of controls; and [4] in COPD eosinophils appear as a possible central regulatory cell relating immunity and repair with lung function abnormalities and emphysema.

\section{Previous studies}

Some previous reports have shown reduced BM-derived circulating progenitors (CD34+ cells) in patients with COPD, particularly in those with more severe airflow 
limitation, arterial hypoxemia and low-BMI $[12,14]$. On the other, Broekman et al. recently described that the immune-phenotype, growth, differentiation and migration capacity of BM progenitor cells were not different between 9 COPD patients and 9 age-matched, never-smoking, controls [15]. The results of our pair wise analysis (Table 1) are in keeping with this latter report. However, our study extends all these previous studies by including a larger number of patients and controls and, specially, by using, for the first time, multilevel network analysis to get a holistic understanding of the system, both at the BM, circulating blood and physiologic levels.

\section{Interpretation of results}

Despite that, by and large, we did not find significant pair wise differences between groups in the different immune-phenotypic, proliferation and differentiation, inflammatory or repair markers, neither in BM or circulating blood (Table 1), the use of multi-level correlation network analysis provided several observations of interests. Firstly, it identifies a module in which B-cells, progenitor cells (CD34+) and eosinophils interact in the whole population, as well as a second module that relates lung function parameters with immunity and repair nodes. Secondly, the network was more interconnected, hence more complex and developed, in COPD patients than in controls (Fig. 2 and Additional file 1: Figure S1), suggesting chronic system activation in COPD. The difference might, however, be due to the higher cumulated smoking history of COPD patients, as we have observed a denser network when comparing networks of patients with Pack-Years $\geq 45$ versus Pack-Years $<45$ (Additional file 5: Figure S4).Thirdly, the COPD correlation network was more fragmented in those patients with emphysema (DLCO $<60 \%$ reference) or $\geq 300$ circulating Eos $/ \mu \mathrm{L}$, indicating reduced system resilience [21] and potentially impaired repair capacity. This is consistent with the accepted pathogenesis of emphysema [28, 29] but highlights a novel patho-biological effect of eosinophils in the lung maintenance program. In fact, supporting this hypothesis and in keeping with previous studies [30, 31], we found that COPD patients with $\geq 300 \mathrm{Eos} / \mu \mathrm{L}$ had worse lung function and less BM HSCs (Table S2), suggesting deficient $\mathrm{BM}$ repair response. In support of this hypothesis is the recent observation in the COPDgene cohort of a relation between biomarkers of extracellular matrix turnover, emphysema and eosinophilic-bronchitis in patients with COPD [27]. Moreover, other studies have found involvement of eosinophils in colonic inflammation and repair [26]. The finding of eosinophils as cells that are present in almost all the networks being one of the most connected hubs in each network and also the different number of compartments in which it was involved (as clinical variables, blood cytokines, bone marrow surface markers) made us to consider the role of eosinophil as a possible regulatory cell.

Finally, we did not find differences in the bivariate analysis between different growth factors but the network analysis showed relationships among HGF, VEGF, TGF, EPCs, eosinophils and lung function parameters. It has been recently described that human mesenchymal stromal cells exert HGF dependent cytoprotective effects in a human relevant pre-clinical model of COPD [6], that is consistent with the role of HGF in the network connected with DLCO, FEV1 and EPC. Moreover, impaired VEGF signaling has been associated with emphysema in animal models [7] and our network shows an inverse correlation with EPC which could be explained as a consequence of the impaired repair mechanisms in these patients.

\section{Strengths and limitations}

The use, for the first time, of network analysis to understand the BM system in a large cohort of COPD patients and controls is a clear strength of our study. It also has, however, some potential limitations that deserve comment. First, because COPD patients (and controls) required cardio-thoracic surgery for clinical reasons (with different indication for cases and controls), results may not be automatically generalised. Second, as discussed above, we studied a higher number of COPD patients than controls, and this may influence the structure of correlation networks [25]. To address this, we increased the number of controls by merging smokers and never smokers, and yet found similar results. However, we still could not correct for the effect of active smoking due to the sample size. Third, network density is also directly proportional to the threshold chosen for statistical significance, the lower the $p$ value, the higher network density. To get an appropriate signal to noise balance, as others have done before [16, 21], we established an arbitrary $\mathrm{p}$ threshold value of less than 0.01 , so weaker relationships were not included in the network. Fourth, although the data point to eosinophil as a possible mediator of the immune and repair response, especially in patients with emphysema, the authors cannot exclude the presence of other co-mediators and further studies are needed to demonstrate the role of these cells in the repair process of the lung. In keeping with this, due to the sample size we could not explore the effects of inhaled corticosteroids, that some of these patients were receiving, on the BM characteristics. Finally, we studied only one source of stem cells, namely the BM, while there are other organs also able to produce these cells, such as the spleen or even the lung themselves [32].

\section{Conclusions}

These results suggest that BM seems to be chronically activated in COPD, despite there are not differences in 
the baseline structure and function between COPD and controls. Moreover, the resilience and repair capacity of the system can be impaired in patients with more emphysema and/or higher circulating Eos.

\section{Additional files}

Additional file 1: Figure S1. Multi-level correlation network of COPD patients and merged controls (smokers and non-smokers with normal spirometry). For further explanations, see text. Abbreviations: Abs: absolute count; HSC: Hematopoietic stem cells, TNF R80: Tumour necrosis factor receptor p80; HGF: Hepatocyte growth factor; VEGF: Vascular endothelial growth factor, IL: Interleukin; RBC: Red blood cells; WBC: White blood cells; Lympho: Lymphocytes; Segmented: segmented neutrophils; E. Polychrom: Polychromatic erythroblast; E. Basophils: Basophils erythroblast; E. Ortochrom: Ortochromatic erythroblast; B cells: B lymphocytes; $\mathrm{Hb}$ : haemoglobin, Eos: Eosinophils; Mono/Macro: Monocyte/Macrophages; MFI: Mean fluorescence intensity; Neutro: Neutrophil; FEV1: forced expiratory volume in 1st second; DLCO: Diffusing capacity of the lung for carbon monoxide, BMI: body mass index. (JPG $51 \mathrm{~kb}$ )

Additional file 2: Figure S2. Multi-level correlation network of COPD patients with DLCO $\geq 60 \%$ or $<60 \%$. For further explanations, see text. Abbreviations: Abs: absolute count; HSC: Hematopoietic stem cells; EPC: Endothelial progenitor cells; TNF R80: Tumour necrosis factor receptor p80; TGF-ß: Transforming growth factor beta; HGF: Hepatocyte growth factor; VEGF: Vascular endothelial growth factor; IGF: Insulin-like growth factor; RBC: Red blood cells; Lympho: Lymphocytes; Segmented: segmented neutrophils; E. Polychrom: Polychromatic erythroblast; E. Ortochrom: Ortochromatic erythroblast; B cells: B lymphocytes; Plasmatic: Plasmatic cells; Hb: haemoglobin; Eos: Eosinophils; Mono/Macro: Monocyte/Macrophages; MFI: Mean fluorescence intensity; Mono: Monocyte; Neutro: Neutrophil; FEV1: forced expiratory volume in 1st second; DLCO: Diffusing capacity of the lung for carbon monoxide; BMl: body mass index. (JPG $60 \mathrm{~kb}$ )

Additional file 3: Table S1. Bone marrow characterization, inflammatory and repair markers (mean \pm SD or median [IQR]) in COPD patients with DLCO higher or lower than $60 \%$ of reference. Bolded italic text highlight variables with statistically significant differences ( $p \leq 0.05$ ). Table S2. Bone marrow characterization, inflammatory and repair markers (mean \pm SD or median [IQR]) in COPD patients with peripheral blood eosinophil counts $<300$ or $\geq 300 / \mu \mathrm{L}$. Bolded italic text highlight variables with statistically significant differences ( $p \leq 0.05$ ). (DOCX $42 \mathrm{~kb}$ )

Additional file 4: Figure S3. Multi-level correlation network of COPD patients with peripheral blood eosinophil counts $<300 / \mu \mathrm{L}$ or $\geq 300 / \mu \mathrm{L}$. For further explanations, see text. Abbreviations: Abs: absolute count; HSC: Hematopoietic stem cells; EPC: Endothelial progenitor cells; TNF R80: Tumour necrosis factor receptor p80; VEGF: Vascular endothelial growth factor; RBC: Red blood cells; WBC: White blood cells; Lympho: Lymphocytes; Segmented: segmented neutrophils; E. Ortochrom: Ortochromatic erythroblast; T cells: T lymphocytes; Plasmatic: Plasmatic cells; Mono/ Macro: Monocyte/Macrophages; Mono: Monocyte; Neutro: Neutrophil; FEV1: forced expiratory volume in 1st second; DLCO: Diffusing capacity of the lung for carbon monoxide; BMI: body mass index. (JPG $53 \mathrm{~kb}$ )

Additional file 5: Figure S4. Multi-level correlation network of COPD patients with smoking history $<45$ pack-years or $\geq 45$ pack-years. For further explanations, see text. Abbreviations: Abs: absolute count; HSC: Hematopoietic stem cells; TNF: Tumour necrosis factor; VEGF: Vascular endothelial growth factor; HGF: Hepatocyte growth factor; LL: Interleukin; RBC: Red blood cells; WBC: White blood cells; Lympho: Lymphocytes; B cells: B lymphocytes; T cells: T lymphocytes; Mono: Monocyte; Neutro: Neutrophil; Segmented: segmented neutrophils; Eos: Eosinophils; E. Ortochrom: Ortochromatic erythroblast; E. Polychrom: Polychromatic enythroblast; FEV1: forced expiratory volume in 1szt second; DLCO: Diffusing capacity of the lung for carbon monoxide; BMl: body mass index. (JPG $59 \mathrm{~kb})$

\section{Abbreviations}

BM: Bone marrow; BMl: Body mass index; COPD: Chronic obstructive pulmonary disease; CRP: C-reactive protein; DLCO: Carbon monoxide diffusing capacity; ELISA: Enzyme-Linked Immunosorbent Assay; Eos: Eosinophil; EPC: Endothelial progenitor cells; FEV1: Forced expiratory volume in the first second; HGF: Hepatocyte growth factor; HSC: Hematopoietic stem cells; IGF: Insulin-like growth factor; IL: Interleukin; M $\varphi$ : Macrophage; TGF- $\beta$ : Transforming growth factor beta; VEGF: Vascular endothelial growth factor

\section{Acknowledgements}

Authors thank the participants in this study for their willingness to contribute to medical research. Authors also thank Dr. Laura Vidal, and all the Cardiothoracic surgery team of Hospital Universitari Son Espases (Palma de MaIlorca, Spain) for their help during BM aspiration.

\section{Funding}

This study has been supported, in part, by Fondo de Investigación Sanitaria, Instituto Carlos III (PI08/0780), CIBERES and beca SEPAR.

\section{Availability of data and materials}

The datasets used and/or analysed during the current study are available from the corresponding author on reasonable request.

\section{Authors' contributions}

N.T-P and BG.C designed the study, had full access to all of the data in the study and take responsibility for the integrity of the data and the accuracy of the data analysis. N.T-P. served as principal author. N.T, G.N, A.J, A.I, MA.D, J.I, A.R, S.S, R.F, O.G, A.A and BG.C contributed to data collection and interpretation; N.T-P performed the statistical analyses; finally N.T-P, BG.C, and A.A drafted the first manuscript, and finally approved this submission.

\section{Ethics approval and consent to participate}

The study was approved by the Ethics Committee of the Balearic Islands ( $\mathrm{Cl}-$ IB number 849/07) and all participants signed their informed consent.

\section{Consent for publication}

Not applicable.

\section{Competing interests}

Dr. Agusti reports, outside the submitted work, grants and personal fees from Astra-Zeneca, GSK and Menarini, grants from MSD and personal fees from Novartis, TEVA and Chiesi. Dr. Cosio reports personal fees from AstraZeneca, Rovi and Esteve, grants from Boehringer and grants and personal fees from Novartis, Chiesi and Menarini, all of them outside the submitted work. All the other authors have no conflict of interest to declare.

\section{Publisher's Note}

Springer Nature remains neutral with regard to jurisdictional claims in published maps and institutional affiliations.

\section{Author details}

${ }^{1}$ CIBER Enfermedades Respiratorias (CIBERES), Instituto de Salud Carlos III, Madrid, Spain. ${ }^{2}$ Department of Respiratory Medicine, Hospital Universitari Son Espases-IdISBa, Valldemossa 79, 07010 Palma de Mallorca, Spain. ${ }^{3}$ Institut d'investigacions Biomèdiques August Pi i Sunyer (IDIBAPS), Barcelona, Spain. ${ }^{4}$ Department of Hematology, Hospital Universitari Son Espases-IdISBa, Mallorca, Spain. ${ }^{5}$ Department of Immunology, Hospital Universitari Son Espases-IdISBa, Mallorca, Spain. ${ }^{6}$ Department of Thoracic Surgery, Hospital Universitari Son Espases-IdISBa, Mallorca, Spain. ${ }^{7}$ Department of Medicine, Universitat de Barcelona, Barcelona, Spain. ${ }^{8}$ Respiratory Institute, Hospital Clinic, University of Barcelona, Barcelona, Spain.

Received: 22 February 2018 Accepted: 8 June 2018

Published online: 15 June 2018

\section{References}

1. Anthony B, Link DC. Regulation of hematopoietic stem cells by bone marrow stromal cells. Trends Immunol. 2014;35:32-7.

2. Osumi N, Shinohara H, Numayama-Tsuruta K, Maekawa M. Concise review: Pax6 transcription factor contributes to both embryonic and adult neurogenesis as a multifunctional regulator. Stem Cells. 2008;26:1663-72.

3. Kim E-K, Lee J-H, Jeong H-C, Oh D, Hwang S-G, Cho Y-W, Lee S-J, Oh Y-M, AS-D L. Impaired Colony-forming capacity of circulating endothelial 
progenitor cells in patients with emphysema. Tohoku J Exp Med. 2012;227 321-31.

4. Rafii S, Lyden D. Therapeutic stem and progenitor cell transplantation for organ vascularization and regeneration. Nat Med. 2003;9(6):702-12

5. Peichev M, Naiyer AJ, Pereira D, Zhu Z, Lane WJ, Williams M, Oz MC, Hicklin DJ, Witte L, Moore MAS, Rafii S. Expression of VEGFR-2 and AC133 by circulating human CD34 (+) cells identifies a population of functional endothelial precursors. Blood. 2000;95(3):952-8.

6. Kennelly $\mathrm{H}$, Mahon BP, English K. Human mesenchymal stromal cells exert HGF dependent cytoprotective effects in a human relevant pre-clinical model of COPD. Sci Rep. 2016;6:38207.

7. Bakakos P, Patentalakis G, Papi A. Vascular biomarkers in asthma and COPD. Curr Top Med Chem. 2016;16:1599-609.

8. López IP, Piñeiro-Hermida S, Pais RS, Torrens R, Hoeflich A, Pichel JG. Involvement of Igf1r in bronchiolar epithelial regeneration: role during repair kinetics after selective club cell ablation. PLoS One. 2016;11:1-32.

9. Gao C, Maeno T, Ota F, Ueno M, Korekane H, Takamatsu S, Shirato K Matsumoto A, Kobayashi S, Yoshida K, Kitazume S, Ohtsubo K, Betsuyaku T, Taniguchi N. Sensitivity of heterozygous alpha1,6-fucosyltransferase knockout mice to cigarette smoke-induced emphysema: implication of aberrant transforming growth factor-beta signaling and matrix metalloproteinase gene expression. J Biol Chem. 2012;287:16699-708.

10. Di Stefano A, Sangiorgi C, Gnemmi I, Casolari P, Brun P, Ricciardolo FLM, Contoli M, Papi A, Maniscalco P, Ruggeri P, Girbino G, Cappello F, Pavlides S, Guo Y, Chung KF, Barnes PJ, Adcock IM, Balbi B, Caramori G. TGF- $\beta$ signaling pathways in different compartments of the lower Airways of Patients with Stable COPD. Chest. 2017;153:851-62.

11. From the Global Strategy for the Diagnosis, Management and Prevention of COPD, Global Initiative for Chronic Obstructive Lung Disease (GOLD) 2017. Available from: http://goldcopd.org.

12. Palange $P$, Testa $U$, Huertas A, Calabrò L, Antonucci R, Petrucci E, Pelosi E, Pasquini L, Satta A, Morici G, Vignola MA, Bonsignore MR. Circulating haemopoietic and endothelial progenitor cells are decreased in COPD. Eur Respir J. 2006;27:529-41.

13. Janssen WJ, Yunt ZX, Muldrow A, Kearns MT, Kloepfer A, Barthel L, Bratton DL, Bowler RP, Henson PM. Circulating hematopoietic progenitor cells are decreased in COPD. COPD. 2014;11:277-89.

14. Huertas A, Testa U, Riccioni R, Petrucci E, Riti V, Savi D, Serra P, Bonsignore $M R$, Palange $P$. Bone marrow-derived progenitors are greatly reduced in patients with severe COPD and low-BMI. Respir Physiol Neurobiol. 2010;170: 23-31.

15. Broekman W, Roelofs H, Zarcone MC, Taube C, Stolk J, Hiemstra PS. Functional characterisation of bone marrow-derived mesenchymal stromal cells from COPD patients. ERJ open Res. 2016;2:1-10.

16. Faner R, Cruz T, Casserras T, Lopez-Giraldo A, Noell G, Coca I, Tal-Singer R, Miller B, Rodriguez-Roisin R, Spira A, Kalko SG, Agusti A. Network analysis of lung transcriptomics reveals a distinct B-cell signature in emphysema. Am J Respir Crit Care Med. 2016;193:1242-53.

17. Bafadhel M, McKenna S, Terry S, Mistry V, Reid C, Haldar P, McCormick M, Haldar K, Kebadze T, Duvoix A, Lindblad K, Patel H, Rugman P, Dodson P, Jenkins $M$, Saunders M, Newbold P, Green RH, Venge P, Lomas DA, Barer MR, Johnston SL, Pavord ID, Brightling CE. Acute exacerbations of chronic obstructive pulmonary disease: identification of biologic clusters and their biomarkers. Am J Respir Crit Care Med. 2011;184:662-71.

18. Cosio BG, Soriano JB, López-Campos JL, Calle-Rubio M, Soler-Cataluna Jر J De-Torres JP, Marín JM, Martínez-Gonzalez C, De Lucas P, Mir I, Peces-Barba G, Feu-Collado N, Solanes I, Alfageme I, Casanova C. Defining the asthmaCOPD overlap syndrome in a COPD cohort. Chest. 2016;149:45-52.

19. Miller MR, Hankinson J, Brusasco V, Burgos F, Casaburi R, Coates A, Crapo R, Enright P, van der Grinten CPM, Gustafsson P, Jensen R, Johnson DC, Maclntyre N, McKay R, Navajas D, Pedersen OF, Pellegrino R, Viegi G, Wanger J. Standardisation of spirometry. Eur Respir J. 2005;26:319-38.

20. Macintyre N, Crapo RO, Viegi G, Johnson DC, van der Grinten CPM, Brusasco V, Burgos F, Casaburi R, Coates A, Enright P, Gustafsson P, Hankinson J, Jensen R, McKay R, Miller MR, Navajas D, Pedersen OF, Pellegrino R, Wanger J. Standardisation of the single-breath determination of carbon monoxide uptake in the lung. Eur Respir J. 2005;26:720-35.

21. Noell G, Cosío BG, Faner R, Monsó E, Peces-Barba G, de Diego A, Esteban C, Gea J, Rodriguez-Roisin R, Garcia-Nuñez M, Pozo-Rodriguez F, Kalko SG, Agustí A. Multi-level differential network analysis of COPD exacerbations. Eur Respir J. 2017;50:1700075.
22. Barabasi A-L, Gulbahce N, Loscalzo J. Network medicine: a network-based approach to human disease. Nat Rev Genet. 2011;12:56-68.

23. Diez D, Agusti A, Wheelock CE. Network analysis in the investigation of chronic respiratory diseases. From basics to application. Am J Respir Crit Care Med. 2014;190:981-8

24. Shannon P, Markiel A, Ozier O, Baliga NS, Wang JT, Ramage D, Amin N, Schwikowski B, Ideker T. Cytoscape: a software environment for integrated models of biomolecular interaction networks. Genome Res. 2003;13:2498504.

25. Goertzen JR, Cribbie RA. Detecting a lack of association: an equivalence testing approach. Br J Math Stat Psychol. 2010;63:527-37.

26. Hadar R, Itay M, Michal I, Metsada P-C, Thomas V, Johannes R, Ariel M. Transcriptome profiling of mouse colonic eosinophils reveals a key role for eosinophils in the induction of s100a8 and s100a9 in mucosal healing. Sci Rep. 2017;7:7117.

27. Bihlet AR, Karsdal MA, Sand JMB, Leeming DJ, Roberts M, White W, Bowler R. Biomarkers of extracellular matrix turnover are associated with emphysema and eosinophilic-bronchitis in COPD. Respir Res. 2017;18:22.

28. Lam AP, Gottardi CJ, Tuder R. Regenerative pathways and emphysema: a new paradigm? Am J Respir Crit Care Med. 2011;183:688-90.

29. Tuder RM, Yoshida T, Fijalkowka I, Biswal S, Petrache I. Role of lung maintenance program in the heterogeneity of lung destruction in emphysema. Proc Am Thorac Soc. 2006;3:673-9.

30. Rogliani P, Puxeddu E, Ciaprini C, Ora J, Onorato A, Pezzuto G, Calzetta L, Cazzola M. The time course of pulmonary function tests in COPD patients with different levels of blood eosinophils. Biomed Res Int. 2016;2016

31. Queiroz CF, Lemos ACM, Bastos M de LS, Neves MCLC, Camelier AA, Carvalho NB, de CEM. Inflammatory and immunological profiles in patients with COPD: relationship with FEV 1 reversibility. J Bras Pneumol. 2016;42: 241-7.

32. Lefrançais E, Ortiz-Muñoz G, Caudrillier A, Mallavia B, Liu F, Sayah DM, Thornton EE, Headley MB, David T, Coughlin SR, Krummel MF, Leavitt AD,

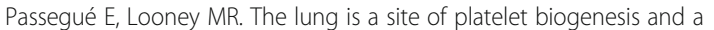
reservoir for haematopoietic progenitors. Nature. 2017;544:105-9.

\section{Ready to submit your research? Choose BMC and benefit from:}

- fast, convenient online submission

- thorough peer review by experienced researchers in your field

- rapid publication on acceptance

- support for research data, including large and complex data types

- gold Open Access which fosters wider collaboration and increased citations

- maximum visibility for your research: over $100 \mathrm{M}$ website views per year

At BMC, research is always in progress.

Learn more biomedcentral.com/submissions 